\title{
Infrared Absorption Spectra of Some Gamma Irradiated Borate Glasses Containing Nickel and Titanium Ions
}

\author{
Z.A. El-Hadi , KH. M. El-Badry ${ }^{*}$, F.A. Moustaffa*, M.A. El- \\ Baki $^{*}$ and H. H. Mahmoud ${ }^{* *}$ \\ Chemistry Department, College for Girls, Ain Shams \\ University, *Glass Research Laboratory, National Research \\ Center and **Rad.Chem. Dept., National Center for Radiation \\ Research \& Technology, Cairo, Egypt.
}
T NFRARED absorption spectroscopy for a number of borate 1 number of borate glasses containing nickel and titanium nickel and titanium ions was carried out before and after subjecting to gamma radiations. All glasses were melted in $\mathrm{Pt}$ - $2 \% \mathrm{Rh}$ crucibles in an electrically heated furnace at $1100^{\circ} \mathrm{C}$ for two hours.

All measurements were recorded using a Jasco FT/IR-300 E infrared spectrophotometer in the range of (4000-200) $\mathrm{cm}^{-1}$.

The response of the glasses studied to $\gamma$-rays radiation is related to the formation, accumulation and annihilation of induced defects and hence the observed changes in the FTIR spectra can be utilized to confirm the changes in the structure arrangements of the building groups after irradiation.

I.R absorption spectra can provide more information on the structure of different types of glasses, the vibrational spectra can be used to identify the glasses for the specific group which are present in it ${ }^{(2,3)}$. Borate glasses provide an ideal case in comparison to other glass forming systems, to demonstrate the effectiveness of UV-visible, infrared and Raman spectroscopy in glass science. First, borate glasses are easily melted and are good hosts for transition metals ions and from a number of spectroscopy techniques, the properties of glasses have been established in terms of stereo chemical environment they provide and the oxidation number that they favor for the transition metal iron ${ }^{(1)}$. These properties can change according to the alkali oxide or modifiers contain ${ }^{(2)}$. With the earlier elements in the first translations series it's found that increasing the alkali oxide content, tends to favor upper oxidation state.

The gamma-ray induced optical absorption in a series of cabal glasses was studied and interpreted in terms of structural concepts by Bishay ${ }^{(4)}$ and it was 
concluded that these induced absorption spectra were affected by the change in the structure, condition of melting and also by small additions of some certain elements which are not normally present as impurities such as titanium or arsenic.

Infrared spectroscopy (IR) is one of the most useful experimental techniques available for structural studies of glasses ${ }^{(1)}$ for the particular case of glasses modified by metal oxides infrared is a powerful tool because it leads to structural aspects related to both the local units constituting the glass net work and the anionic sites hosting the modifying metal cations. Borate glasses provide an ideal case in comparison to other glass forming systems to demonstrate the effectiveness of Infrared spectroscopy in glass science; first boron has the smallest mass compared to other network forming elements and thus the main vibrational modes associated with the glass network appear well above $500 \mathrm{~cm}-1$ in the mid -infrared 2 these network modes are well separated from the metal ion site vibrational modes active in the far infrared region I -e below - $600 \mathrm{~cm}-13-5$, second borates have a rich chemistry because of the ability of boron to change its coordination with oxygen between three and four and this provides a range of anionic environments that can coordinate the modifying metal ions. For these reasons, the borate glass systems can be considered as prototypes for infrared investigations of the short-range order structure of the network in the mid infrared as well as of the metal ion site interactions in the far infrared region of the spectrum.

Bishay et al. ${ }^{(5)}$ concluded that irradiation of silicate glasses containing titania resulted in an additional induced band at about $2.5 \mathrm{eV}$ which was attributed to $\mathrm{Ti}^{+4}$ formed as a result of reduction of $\mathrm{Ti}^{+4}$ by radiation as confirmed by electron spin resonance studies.

Also, Bishay ${ }^{(6)}$ in a review article discussed the nature of color centers induced by radiation in different types of glasses using optical and electron spin resonance techniques and concluded that in glasses, the visible induced absorption was associated with positive whole centers. However, at certain compositions, an electron trap center which absorbs in the visible is also induced by radiation and was associated with certain structural defects, e.g., a non-bridging oxygen ion vacancy neighboring the alkali ion in diborate or disilicate glasses.

The variation of optical density of a few induced absorption bands in some sodium-aluminium borate glasses was studied by Hussein et $a l .{ }^{(7)}$ by varying the radiation doses of gamma rays, different rates of formation of color centers were observed and the attribution of the absorption bands was advanced.

Moustaffa et al. ${ }^{(8)}$ studied the change of optical absorption of some irradiated mixed alkali borate glasses containing nickel oxide by varying the gamma-ray dose or the mixed alkali oxide content and it was concluded that upon irradiation, hole trapped color centers with the characteristic induced visible band at $550 \mathrm{~nm}$ have been developed in the parent and colored glasses. The increase of irradiation Egypt. J. Chem. 54, No. 6 (2011) 
dose increases the intensity of the induced visible absorption and this increase was related to the presence of the lattice defects and impurities in the glass before irradiation.

The radiation induced visible centers in some cabal glasses containing chromium were also studied by Ghoneim et $a l^{(9)}$ with a view toward elucidating the effect of the transition metal on the absorption spectra of these glasses. The results obtained could be attributed to the assumption that during the first stages of irradiation the observed effect is due to the charge trapping at existing defects and any later higher dose effect is due to the creation of the more defect centers.

It was found by Kutub et al. ${ }^{(10)}$ that two radiation induced effects occur in the spectral absorption of $\mathrm{Na}_{2} \mathrm{~B}_{4} \mathrm{O}_{7}$, a shift in the fundamental absorption edge to longer wavelength and the appearance of a stable new absorption band at $550 \mathrm{~nm}$ with its position remaining practically unaffected with increasing radiation dose.

Morinaga et al. ${ }^{(11)}$ measured the absorption spectra of Ti in different types of glasses. The value of the absorption coefficient depends on the basicity in silicate and borate glasses; however it is independent of composition in phosphate glasses.

Villegas et al. ${ }^{(12)}$ prepared calcium silicate glasses containing titania up to 30 mol\%; and found that the thermal expansion coefficient was lower than those of conventional soda-lime glasses due to the presence of Ti- 0 bonds which are weaker than $\mathrm{Si}-0$ bonds in the glass network, and which increase the mobility of the structure. Titanium ions could be introduced into the glass structure as tetrahedral units $\left(\mathrm{TiO}_{4}\right)$ replacing silica tetrahedra or as octahedral coordination $\left(\mathrm{TiO}_{6}\right)$ depending on the glass composition. Also, the addition of $\mathrm{TiO}_{2}$ enhanced microhardness, toughness and alkali resistant of glass.

Harder et al. ${ }^{(13)}$ investigated the infrared absorption spectra of some lead borate glasses and stated that the mid infrared spectra supply information about the content of the structural borate groups independence of the lead oxide concentration; it was also stated that the far infrared show a band of the $\mathrm{Pb}^{+2}$ cation vibrations within the glass network between 190 and $100 \mathrm{~cm}^{-1}$.

Witke et $a l .{ }^{(14)}$ prepared and investigated some lead borate and lead alumino borate glasses by infrared spectroscopy technique to obtain quantitative and qualitative information on the structure of these glasses.

Spectrophotometric studies on some lead borate glasses containing chromium oxide before and after being subjected to gamma rays irradiation were carried out by El-Badry et al. ${ }^{(15)}$. The results obtained revealed absorption bands characteristic for the state of the transition metal oxide content in the glasses studied. The change in the growth rate of the induced defects with radiation was discussed.

Optical absorption of some gamma irradiated lead silicate glasses containing chromium was studied by Moustaffa et al. ${ }^{(16)}$. The results obtained revealed that 
upon increasing the irradiation dose, different rates of the color center formation were observed and the intensity of absorption increased till it reached the plateau shape or saturation state at the maximum irradiation dose. These measurements are aimed to throw some light on the structure of these glasses and the forms in which the nickel and titanium ions exist in glass.

\section{Experimental}

Some zinc oxide or barium oxide-sodium borate glasses containing $0.2 \mathrm{~g}$ nickel oxide and $1.0 \mathrm{~g}$ titanium oxides were prepared. The raw materials used were of chemically pure grade and were finely pulverized. Boric oxide was introduced in the form of boric acid. Soda and barium oxide were introduced in the form of their respective carbonate while zink, nickel and titanium oxides were introduced as such. All the replacements were made on the cation for cation basis.

The melts were made in $\mathrm{Pt}-2 \% \mathrm{Rh}$ crucibles in an electrically heated furnace. The temperature of melting was $1100^{\circ} \mathrm{C}$ while the duration of melting was two hours. After complete melting, each glass melt was cast into special stainless steel molds and the prepared glass samples were annealed at the appropriate temperature (350$400)^{\circ} \mathrm{C}$, then the glass samples were ground using an agate mortar.

All the glasses under investigation were exposed to gamma radiation using an Indian $\mathrm{Co}^{60}$ gamma rays cell $(2000 \mathrm{Ci})$ with a dose rate of about $2.3 \mathrm{~Gy} / \mathrm{sec}$. in which each glass sample was placed in a manner that it was subjected to the same irradiation dose. The required dose was achieved by calculating the desired overall dose.

Spectrophotometeric measurements in the infrared region of the spectrum were recorded in the range of (4000-200) $\mathrm{cm}^{-1}$ using a Jasco FT/IR-300E infrared spectrophotometer. The alkali halide disc technique at $27^{\circ} \mathrm{C}$ was used. Also, potassium bromide reference disc was maintained at that temperature.

The experimental results obtained were plotted in terms of optical absorption as a function of wave number in $\mathrm{cm}^{-1}$.

\section{Results}

1. The infrared absorption spectra of the parent sodium borate glass of the composition $\mathrm{B}_{2} \mathrm{O}_{3} 80 \%, \mathrm{Na}_{2} \mathrm{O} 20 \%$, NiO $0.2 \mathrm{~g}, \mathrm{TiO}_{2} 2.0 \mathrm{~g}$ were studied. From which it can be seen that several absorption bands at (3446-2390), 1660, 1440, $1340,1165,1080,940,880,820,700,540,460$ and $[400-300] \mathrm{cm}^{1}$, were observed (Fig. 1).

2. The results obtained from the infrared absorption spectra of the above same base glass subjected to $1.2 \times 10^{6} \mathrm{rad} / \mathrm{sec}$. gamma irradiation revealed several absorption bands at (3431-2350), 1636, 1431, 1353, 1249, 1096, 1028, 922,

Egypt. J. Chem. 54, No. 6 (2011) 
$816,696,512$ and $461 \mathrm{~cm}^{-1}$ as observed in Table 1.

3. The infrared absorption spectra for some substituted sodium borate glasses of the above same base glass composition in which two or ten parts of soda were replaced by one of the divalent metal oxides zinc oxide or barium oxides, cation for cation, subjected to $12 \times 10^{5} \mathrm{rad} / \mathrm{sec}$ gamma irradiation revealed that numerous absorption bands at (3437-2334), (16441632), (1436-1360), (1356-1354), (1250-1248), (1101-1098), (1026-1017), (923-921), (782-780), (697-691), (587-507) and (454-452) $\mathrm{cm}^{-1}$ were observed according to the type and the amount of the divalent metal oxide content, (Table 2).

4. The results obtained from the infrared absorption spectra of the above glasses containing zinc oxide or barium oxide subjected to the different doses of gamma, irradiation ranged from $1 \times 10^{5}$ to $12 \times 10^{5} \mathrm{rad} / \mathrm{sec}$ revealed that several absorption bands at (3440-2334), (1645-1626), (1437-1434), (1381-1354), (1251-1213), (1165-1098), (1046-1000), (931-924), 782-695, (593-582), (513-507) and (472-454) $\mathrm{cm}^{-1}$ were observed according to the type and the amount to the dose of the gamma, irradiation (Table 3).

5. The positions and the intensities of the infrared absorption bands slightly changed with the increase either with the increase of the divalent metal oxide content or with the increase of the gamma irradiation dose of gammairradiation ranged from Ix105 to $12 \times 105 \mathrm{rad} / \mathrm{sec}$ revealed that several absorption bands at (3440-2334), (1645-1626), (1437-1434), (1381-1354), (1251-1213), (1165-1098), (1046-1000), (931-924), (782,695), (593-582), (513-507) and (472-454) $\mathrm{cm} " 1$ were observed according to the type and also according to the dose of the gamma-irradiation (Table 3 ). The positions and the intensities of the most infrared absorption band slightly changed with the increase of the gamma irradiation dose.

Fig. 1. Infrared absorption spectra for a number of sodium borate glass containing $0.2 \mathrm{~g} \mathrm{NiO}$ and $\mathrm{TiO}_{2} / 100 \mathrm{~g}$ glass. 


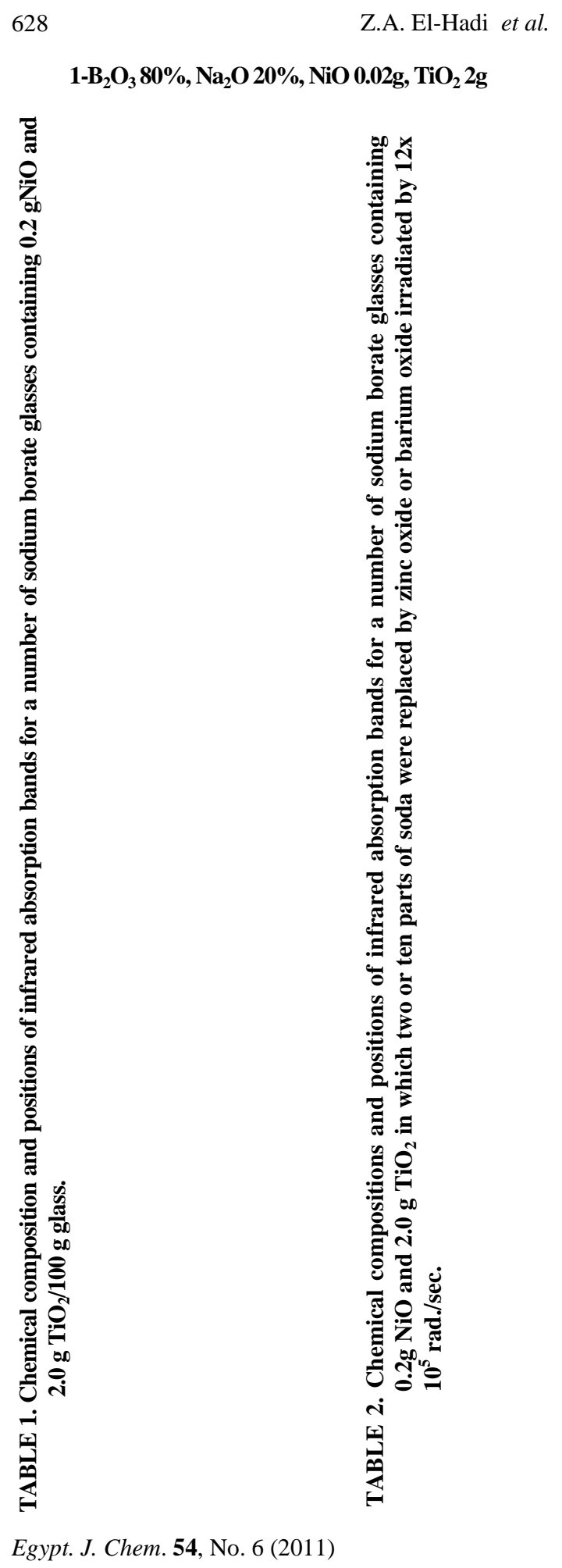




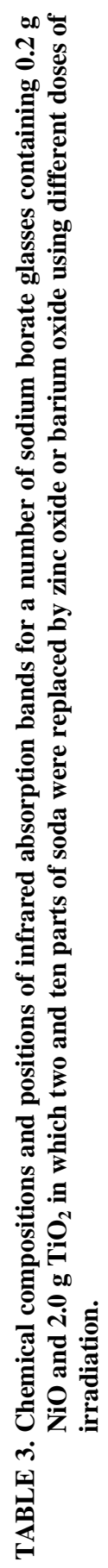




\section{Discussion}

The predominante effect of radiation on inorganic solids ${ }^{(28)}$ is to displace the atoms or the ions producing defects in the lattice structure. This effect is becoming increasingly important with the widespread use of the semiconductor devices in the radiation field and also in the extraterrestrial communications.

There are two reasons for the interest in the effects of radiation on the glass; firstly the effect of radiation is in itself important because the glass is much widely used as a material of construction and secondly it is a useful method for investigating the glass structure.

Infrared absorption spectroscopy can be used as one of the most useful tools available for studying the molecular structure and identifying the unknown substance $^{(29)}$.

Accordingly, the experimental results obtained can be discussed as follows:

1- In the parent sodium borate glass of the composition $\mathrm{B}_{2} \mathrm{O}_{3} 80 \%, \mathrm{Na}_{2} \mathrm{O} 20 \%$, $\mathrm{NiO} 0.2 \mathrm{~g}, \mathrm{TiO}_{2} 2.0 \mathrm{~g}$, the infrared absorption band observed at (3446-2390), $1660,1440,1340,1165,1080,940,880,820,700,460$ and $(400-300) \mathrm{cm}^{-1}$ may be attributed to the fundamental free $\mathrm{OH}$-stretching vibrations ${ }^{(30)}$ or to very strongly hydrogen bonded $\mathrm{OH}$-stretching vibration, $\mathrm{H}_{2} \mathrm{O}$ bending vibrations $^{(31)}$, B-O symmetric stretching vibration of various borate groups ${ }^{(32)}$, stretching vibration of meta borate groups B-O band stretching of trigonal $\mathrm{BO}_{2}{ }^{(33)}$ units, $\mathrm{B}-\mathrm{O}$ asymmetric stretching vibration of tetrahedral $\mathrm{BO}_{4}$ unit ${ }^{(34)}$, vibrations of diborate groups ${ }^{(35)}$ or vibrational band of titanium group $\mathrm{TiO}_{4}$ tetrahedral $^{(36)}$, stretching vibrations of tri, tetra and pentaborate groups ${ }^{(34)}$, titanium oxide vibration in $\mathrm{TiO}_{4}$ tetrahedral ${ }^{(34)}$ band bending vibrations of bridging oxygen atoms ${ }^{(37)}$ or Ti-O-Ti symmetrical vibrations ${ }^{(38)}$, common features for glasses with high boric oxide content ${ }^{(32)}$, the motion of the sodium ion $^{(34)}$ and bending modes for titanate units ${ }^{(39)}$ or vibrational band of titanium groups $^{(40)}$, respectively.

2- The infrared absorption bands for the above same base glass subjected to $12 \times 10^{5} \mathrm{rad} / \mathrm{sec}$ gamma irradiation observed at (3431-2350), 1636, 1431, $1353,1249,1096,1028,922,816,696,512$ and $461 \mathrm{~cm}^{-1}$ may be due to the fundamental free $\mathrm{OH}$-stretching vibrations ${ }^{(30)} \mathrm{H}_{2} \mathrm{O}$ bending vibrations ${ }^{(31)}$, B-O symmetric stretching vibrations of various borate groups, stretching vibrations of metaborate groups, B-O stretching involving mainly the linkages oxygen connecting different groups ${ }^{(33,34)}$, B-O asymmetric stretching vibrations of tetrahedral $\mathrm{BO}_{4}$ units ${ }^{(36)}$, $\mathrm{B}-\mathrm{O}$ stretching vibration of $\mathrm{BO} 4$ tetrahedral in pentaborate units ${ }^{(36)}$, vibrations of diborate groups ${ }^{(37)}$ or vibrational band of titanium groups $\mathrm{TiO}_{2}$ tetrahedra ${ }^{(38)}$, deformation modes of network structure ${ }^{(33)}$, oxygen atom ${ }^{(39)}$ or Ti-O-Ti symmetrical vibrations ${ }^{(40)}$ common features for glasses with high boric oxide content ${ }^{(32)}$ and band due to the motion of the sodium ion ${ }^{(36)}$, respectively (Table 1).

Egypt. J. Chem. 54, No. 6 (2011) 
3- The infrared absorption bands for some sodium borate glasses of the above same base composition containing zinc oxide or barium oxide replacing parts of soda, cation for cation, subjected to $12 \times 10^{5}$ rad./sec gamma irradiation observed at (3437-2334), (1644-1632), (1436-1360), (1356-1354), (12501248), (1101-1098), (1026-1017), (923-921), (782-780), (697-691), (587507) and $452 \mathrm{~cm}^{-1}$ may be due to the fundamental free $\mathrm{OH}$-stretching vibrations ${ }^{(30)}, \mathrm{H}_{2} \mathrm{O}$ bending vibrations, B-O symmetric stretching vibrations of various borate groups, stretching vibrations of metaborate groups ${ }^{(32)}$, B-O stretching involving mainly the linkages oxygen connecting different groups ${ }^{(17,18)}, \mathrm{B}-\mathrm{O}$ asymmetric stretching vibrations of tetrahedral BO4 units, B$\mathrm{O}$ stretching vibrations of $\mathrm{BO}_{4}$ tetrahedra in pentaborate units, vibrations of diborate groups or vibrational band of titanium group $\mathrm{TiO}_{2}$ tetrahedral ${ }^{(22)}$ oxygen bridge between one tetrahedral and one trigonal boron atoms ${ }^{(23)}$, oxygen atoms ${ }^{(24)}$ or Ti-O-Ti symmetrical vibration ${ }^{(25)}$, common features for glasses with high boric oxide content ${ }^{(17)}$ and band due to the motion of the sodium ion ${ }^{(20)}$, respectively (Table 2 ).

Fig. 2. Infrared absorption spectra for a number of sodium borate glass containing $0.2 \mathrm{~g} \mathrm{NiO}$ and $\mathrm{TiO}_{2} / 100 \mathrm{~g}$ glass.

$1-\mathrm{B}_{2} \mathrm{O}_{3} 80 \%, \mathrm{Na}_{2} \mathrm{O} 20 \%$, $\mathrm{NiO} 0.02 \mathrm{~g}, \mathrm{TiO}_{2} 2 \mathrm{~g}$

Fig. 3. Effect of gamma irradiation doses on the infrared absorption spectra of sodium borate

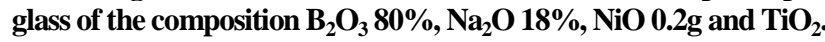
$2 \mathrm{~g}, \mathrm{ZnO}, 2 \% \mathrm{Na}_{2} \mathrm{O} / 100 \mathrm{~g}$ glass. 
3- $12 \times 10^{5} \mathrm{rad} / \mathrm{sec}$.

Fig. 4. Effect of gamma irradiation doses on the infrared absorption spectra of sodium borate glass of the composition $\mathrm{B}_{2} \mathrm{O}_{3} 80 \%, \mathrm{Na}_{2} \mathrm{O} 10 \%$, $\mathrm{NiO} 0.2 \mathrm{~g}$ and $\mathrm{TiO}_{2}$.

$2 \mathrm{~g}, \mathrm{ZnO}, 10 \% \mathrm{Na}_{2} \mathrm{O} / 100 \mathrm{~g}$ glass.

4- $12 \times 10^{5} \mathrm{rad} / \mathrm{sec}$.

Fig. 5. Effect of gamma irradiation doses on the infrared absorption spectra of sodium borate glass of the composition $\mathrm{B}_{2} \mathrm{O}_{3} 80 \%, \mathrm{Na}_{2} \mathrm{O} 18 \%$, $\mathrm{NiO} 0.2 \mathrm{~g}$ and $\mathrm{TiO}_{2}$.

$2 \mathrm{~g}, \mathrm{BaO} 10 \% \mathrm{Na}_{2} \mathrm{O} / 100 \mathrm{~g}$ glass.

5- $12 \times 10^{5} \mathrm{rad} / \mathrm{sec}$.

Fig. 6. Effect of gamma irradiation doses on the infrared absorption spectra of sodium borate glass of the composition $\mathrm{B}_{2} \mathrm{O}_{3} 80 \%, \mathrm{Na}_{2} \mathrm{O} 10 \%$, $\mathrm{NiO} 0.2 \mathrm{~g}$ and $\mathrm{TiO}_{2} 2 \mathrm{~g}, \mathrm{BaO}$, $10 \% \mathrm{Na}_{2} \mathrm{O} / 100 \mathrm{~g}$ glass.

Egypt. J. Chem. 54, No. 6 (2011) 


\section{6- $12 \times 10^{5} \mathrm{rad} / \mathrm{sec}$.}

4- The infrared absorption bands observed, for the above glass containing zinc oxide or barium oxide subjected to the different doses of gamma-irradiation ranged from $\mathrm{Ix} 10^{5}$ to $12 \times 10^{5} \mathrm{red} / \mathrm{sec}$ can be attributed as above.

i- The role of zinc oxide or barium oxide can be explained as follows: when zinc oxide is introduced replacing parts of soda in these types of glasses, a considerable proportion of this oxide will be present as $\mathrm{ZnO}_{4}$ groups with some of $\mathrm{Zn}^{2+}$ ion enclosed in the structural interstices and the formation of one $\mathrm{RO}_{4}$ tetrahedron requires an additional oxygen atom or two single bonded oxygen ion which ion can be provided by the sodium ions. The $\mathrm{ZnO}_{4}$ tetrahedron will have in its neighborhood two $\mathrm{Na}^{+}$ion to establish the electroneutrality and such $\mathrm{Na}^{+}$ion will not be in the same state of freedom as when they are enclosed in the interstices made up of $\mathrm{BO} 3$ alone; as a result, the number of $\mathrm{BO}_{4}$ groups decreases and it should be recalled that no $\mathrm{BO}_{4}$ groups will be linked together but are separated by $\mathrm{BO}_{3}$ triangles or bridge linkages. The oxygen ions which are deformed by the zinc cation are said to be less polarized than those deformed by the sodium cation because the oxygen ions are tightly bonded in the former case than the oxygen ions in the latter case and also due to the relatively small size and higher field strength of the $\mathrm{Zn}^{2+}$ ion. If increasing amounts of zinc oxide are introduced in replacement of soda, the proportion of $\mathrm{ZnO}_{4}$ groups will be reduced since less oxygen ions are available from the soda content, an $\mathrm{Zn}^{2+}$ ion will thus become enclosed in the network structure interstices or will act as bridges between the network forming units ${ }^{(4)}$.

ii- When barium oxide is introduced replacing parts of soda in the above types of glasses, the $\mathrm{Ba}^{2+}$ ions will act partly as bridges between the network forming groups and partly enclosed in the structural interstices which will be largers than the average size necessary to enclose $\mathrm{Na}^{+}$ion, thus the divalent $\mathrm{Ba}^{2+}$ ion will be more strongly held in the structural interstices than the monovalent $\mathrm{Na}^{+}$ion. Consequently, the structure tends to develop a series of interstices of more or less regular type surrounding the $\mathrm{Ba}^{2+}$ cation with a proportion of large irregular interstices in which the sodium ions had to be housed; moreover the $\mathrm{Na}^{+}$ions are comparatively weak in the structure and the most of the more regular interstices are occupied by the $\mathrm{Ba}^{2+}$ ion ${ }^{(4)}$.

The role of nickel and titanium oxides can be explained by concluding that there is no evidence for the contribution of the nickel ions in the infrared absorption spectra of the glasses studied since no absorption bands characteristic to the state of the nickel ions were observed, while the titanium ions may be found in a great proportion in the tetrahedral form $\left(\mathrm{TiO}_{4}\right)$ with a little proportion in the octahedral form $\left(\mathrm{TiO}_{6}\right)$. The state of the titanium ions in the glasses studied can be outlined by considering that titanium dioxide can not be considered as a glass network former by itself $\mathrm{f}^{(6)}$ and it has been demonstrated that this oxide may act as a glass network former by forming binary titanate glasses ${ }^{(7)}$. Almost, all reference of $\mathrm{Ti}_{4}$ ions in the glass, these ions can exist in both six-fold and fourfold co-radiations, also it was stated that some glasses at certain compositions do 
not contain titanium ions in the trivalent state ${ }^{(19)}$ (Table 3).

The effect of gamma irradiation can be discussed as follows:

When the glass is exposed to gamma radiation, defects are formed and are trapped in the network. Any impurities in the glass will compete with the intrinsic defects as trapping sites for these carriers. The response of the glass to the gamma ray radiation is related to the rate of formation and accumulation of the induced defects during the progressive irradiation and hence the production of the characteristic color centers. Transition metals, which can be introduced as impurities in the glass, are present in different quantities, various valences and unlike coordination's and may easily change their valences under the action of irradiation.

In the glasses studied, the change in the intensities of the infrared absorption bands specially, the decrease of the same bands after exposure to gamma irradiation doses may be due to the occurrence of some sort of further disorder in the glass structure. The disorder is accompanied by a decrease in the ability of the structural building groups $\mathrm{BO}_{3}$ and $\mathrm{B}_{4}$ to vibrate and reveal their characteristic absorption. This may be interpreted on the basis that successive gamma irradiation on such glasses produces displacements, bond breakage or knock-on damage beside the electrons rearrangement ${ }^{(26)}$. Such defects are believed not to be permanent but of temporary nature. Also, it is accepted that the rate of formation of the induced defects attains saturation or equilibrium state when sufficient induced defects are formed after which the rate of annihilation is accelerated $^{(26,27)}$. When the rate of formation and annihilation becomes nearly equal after prolonged irradiation, the equilibrium or the saturation state is assumed to be established ${ }^{(28,30)}$.

\section{References}

1. Barker, A. S. and Sievers, A. J., Mod. Phys. 47, 1(1975).

2. Condrate (Sr), A. R., "Introduction to Glass Science", Pye, L. D., Stevens, H. and Lacourse, (Ed.) W. Plenum Publishing Corporation, NY (1972).

3. Furukawa, T. and White, W.B., In Twelfth International Congress On Glass, Albuquerque, New Mexico (1980).

4. Bishay, A., J. Am. Ceram. Soc. 44 (6), (1961).

5. Bishay, A. and Gomma, I., Phys. Chem. Glasses, 9 (1968).

6. Bishay, A., J. Non-Cryst. Solids, 3, 54-114 (1970).

7. Hussein, A.L., Moustaffa, F. A., Gomma, I. and Salem, L. R., Ind. J. Pure and Appl. Phys. 19, 1036 (1981).

8. Moustaffa, F.A., Ghoneim, N.A., Zahran, A.H. and Ezz El-Din, F.M., J. NonCryst. Solids, 55, 353-361 (1983).

Egypt. J. Chem. 54, No. 6 (2011) 
9. Ghoneim, N. A., Moustaffa, F. A., Zahran, A. H. and Ezz El-Din, F. M., J. Am. Ceram. Soc. 66 (6), 447 (1983).

10. Ezz El-Din, F., Abdel Azim, A. and Ahmed, A., Medical Phys. 21 (7), (1994).

11. Morinaga, K. and Yoshida. H., J. Am. Ceram. Soc. 77 (12), 3113- 3118 (1994).

12. Villegas, M., de Pablos, A. and Navarro. J., Glass. Tech. 35 (6), 276 (1994).

13. Harder, U., Reich, P. and Willfahrt, M., J. Molecular Structure, 349, 297(1995).

14. Witke, K., Harder, U., Willfahrt, M., Hubert, T. and Reich, P., Glastech. Ber. Glass \& Technol. 69, 5 (1996).

15. El-Badry, Kh. M., Moustaffa, F. A. and El-Batal, H. A., $18^{\text {th }}$ Inter. Cong. On Glass, San Francisco, CA, USA (1998).

16. Moustaffa, F.A., El-Badry, Kh. M. and El-Batal, H. A., Int. Cong. On Glass, SanFrancisco, CA, USA (1998).

17. Moore, H. and Heaton, M., J. Soc. Glass Tech. 41, 28 (1957).

18. Abo El-Azm, A. and Ashour, G., Egypt. J.Chem. 12, 33 (1958).

19. Hanna, R. and Su, G., J. Am. Ceram. Soc. 47, 597 (1964).

20. Krogh Moe, T., Rhyp. Chem. Glasses, 6, 46 (1965).

21. Moggi, R. and Warren, B., I Appl.Cryst. 3, 251 (1970).

22. Ul agarajis and Kayla, J. R., Spectrochimica Acta, 40A (11\12), 1081 (1984).

23. Kamitsos, E., Karakarsides, M. and Chryssikos, G., J. Phys. Chem. 91, 1073 (1987).

24. Khalifa, F., El-Hadi, Z., Ezz El-Din and Moustaffa, F., J. Mat. Sci. Lett. 10, 1132 (1991).

25. El-Shafi, N. and Morsi, M., J. Mat. Sci. 32, 5185 (1997).

26. Kutub, A. and El-Banhawy, M., J. Mat. Sci. 26, 39 (1991).

27. Ezz El-Din, El-Alaily, N., Zahran, A. and El-Batal, H., Indian J. Pure and Appl. Phys. 31, 48 (1993).

28. Chapiro, M., "Radiation Chemistry and Polymeric Systems". Interscience Pub. NY, 12 (1962).

29. Crozier, D. and Douglas, R., Phys. Chem. Glasses, 6, 240 (1965).

30. Scholze, H., Glass Ind . 47 (11), 622 (1966). 
31. Ernsberger, P., Glass Tech. Ber. 32 (3), 61 (1959).

32. Kamitsos, E., Karrakassides, M. and Chryssikos, G., Phys. Chem. Glasses, 90, 4528 (1986).

33. Krogh-Moe, J. Phys. Chem. Glasses, 4, 46 (1966).

34. Kamitsos, E., Patris, A., Karakassides, M. and Chryesikoss, G., J. Non Cryst. Solids, 126, 52 (1990).

35. Fayon, I., Huwie, R. and Glusser, P., Acta Cryst. 41, 1396 (1985).

36. Kusabirake, K., J. Non-Cryst. Solids, 95, 411 (1967).

37. Julien, M. and Balkanski, M., Mat. Sci. Eng. B 307 (1989).

38. Villegas, M. and Fernandez, J., J. Non-Cryst. Solids, 35, 276 (1994).

39. Tawansi, A., Gohar, A., Holland, D. and Shishtawi, N., J. Phys. 21, 7 (1988).

40. El-Badry, Kh., Afifi, M., Moustaffa, F. and Khalil, E., Cent. Glass and Ceram. Bull. 30 (1), 11 (1983).

(Received 21/ 12/ 2010 ; accepted 5/10/2011) 


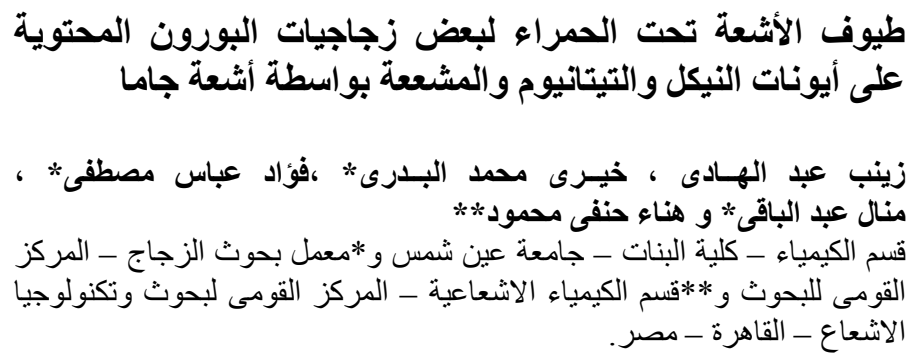

